\title{
EVALUACIÓN IN VITRO DEL EXTRACTO ETANÓLICO DE HOJAS DE BORRAJA (Borago officinalis) CONTRA LA ACTIVIDAD FUNGISTÁTICA
}

\author{
Juan Esteban Villota-Burbano ${ }^{1 / *}$, Olga Yaneth Vazquez-Ochoa ${ }^{2}$ \\ Palabras clave: Fusarium sp; Alternaria sp; ITS; metabolitos secundarios; maleza. \\ Keywords: Fusarium sp; Alternaria sp; ITS; secondary metabolites; weed.
}

Recibido: 15/05/2020

Aceptado: 21/09/2020

RESUMEN

Introducción. Fusarium sp y Alternaria sp son hongos fitopatógenos que causan serios problemas en cultivos y en el sector agrícola, situación que genera pérdidas económicas importantes. Además, debido a la producción de micotoxinas representan una amenaza para la salud de los consumidores y para las plantas. Objetivo. Evaluar la actividad antifúngica del extracto etanólico de hojas de borraja (Borago officinalis) sobre Fusarium sp y Alternaria sp. Materiales y métodos. Se realizó la identificación cualitativa y cuantitativa de los metabolitos secundarios presentes en el extracto etanólico de B. officinalis, posteriormente, Fusarium sp y Alternaria sp. fueron secuenciadas por estudios moleculares mediante la amplificación de la región ITS (espaciador transcribible interno) del ADN ribosomal y finalmente, se evaluó la actividad antifúngica del extracto sobre las cepas previamente reconocidas mediante la prueba de crecimiento radial por técnica de difusión en agar. Resultados. El extracto etanólico de las hojas de B. officinalis contiene alcaloides,

\footnotetext{
* Autor para correspondencia. Correo electrónico: Jvillotab@ucentral.edu.co

1 Universidad Central, Facultad de Ingeniería y Ciencias Básicas, Semillero de Biotecnología ambiental, Bogotá, Colombia. (iD) 0000-0002-1554-3628.
}

\begin{abstract}
In vitro evaluation of ethanol extract from borraja leaves (Borago officinalis) against fungistatic activity. Introduction. Fusarium $\mathrm{sp}$ and Alternaria sp are phytopathogenic fungi that cause serious problems in crops and in the agricultural sector, situation that generates significant economic losses. In addition, due to the production of mycotoxins, they pose a threat to the health of consumers and plants. Objective. To evaluate the antifungal activity of the ethanolic extract of borraja leaves (Borago officinalis) on Fusarium sp and Alternaria sp. Materials and methods. Qualitative and quantitative identification of the secondary metabolites present in the ethanolic extract of $B$. officinalis was carried out, later, Fusarium sp and Alternaria sp were sequenced by molecular studies by amplifying the ITS (internal transcribable spacer) region of ribosomal DNA and finally, antifungal activity of the extract on previously recognized strains was evaluated by means of radial growth test using agar diffusion technique. Results. Ethanolic extract of $B$. officinalis leaves contains
\end{abstract}

2 Universidad Central, Facultad de Ingeniería y Ciencias Básicas, Semillero de Biotecnología ambiental, Bogotá, Colombia.

(D) 0000-0002-3595-8177. 
flavonoides, fenoles, polifenoles y saponinas, de los cuales los polifenoles y los flavonoides presentan una concentración de 19,08 $\pm 0,01$ miligramos equivalentes de ácido gálico (EAG) por gramo de extracto y 28,12 $\pm 0,06$ miligramos equivalentes de catequina (Qe) por gramo de extracto, respectivamente. La secuenciación de los aislamientos evaluados mostró una alta similitud ( $>98 \%$ ) con varias especies de Fusarium sp y Alternaria sp, mientras que los ensayos de actividad antifúngica del extracto mostraron actividad fungistática por parte de $B$. officinalis al ser 16 mg. $\mathrm{l}^{-1}$ el tratamiento más efectivo para ambos aislamientos evaluados con un porcentaje de inhibición de $90,3 \pm 0,9 \%$ para Alternaria sp y $86,6 \pm 2,2 \%$ para Fusarium sp, donde Alternaria sp presentó mayor susceptibilidad frente al extracto de las hojas de B. officinalis. Conclusión. Los resultados de esta investigación proporcionan uno de los primeros reportes de la actividad antifúngica de Borago officinalis sobre Fusarium sp y Alternaria sp.

\section{INTRODUCCIÓN}

Hongos fitopatógenos como Fusarium sp y Alternaria sp producen micotoxinas las cuales provocan daños graves a frutas y vegetales durante los procesos de recolección, transporte y almacenamiento, aspecto que afecta su vida útil, además de hacerlos no aptos para el consumo humano (Galvano et al. 2001, Pavón-Moreno et al. 2012, Tirumale y Wani 2018). Estos hongos son responsables del marchitamiento vascular, decadencia radicular, putrefacción, lesiones necróticas, manchas en hojas y tallos. Asimismo, su presencia también representa una amenaza para la salud de personas consumidoras debido a la producción de micotoxinas (Agrios 2005, Pal y Gardener 2006, Pavón-Moreno et al. 2012).

Colombia representa regiones susceptibles al ataque de organismos fitopatógenos capaces alkaloids, flavonoids, phenols, polyphenols and saponins, of which polyphenols and flavonoids have a concentration of $19.08 \pm 0.01$ milligrams equivalent of gallic acid (EAG) per gram of extract and $28.12 \pm 0.06$ milligrams equivalent of catechin (Qe) per gram of extract, respectively. Molecular sequencing of the evaluated isolates showed a high similarity ( $>98 \%$ ) with several species of Fusarium sp and Alternaria sp, while antifungal activity tests of the extract showed fungistatic activity by $B$. officinalis, with $16 \mathrm{mg} . \mathrm{l}^{-1}$ being the most effective treatment for both isolates evaluated with an inhibition percentage of $90.3 \pm 0.9 \%$ for Alternaria sp and $86.6 \pm 2.2 \%$ for Fusarium sp, where Alternaria sp presented greater susceptibility to the extract of $B$. officinalis leaves. Conclusion. The results of this investigation provide one of the first reports of the antifungal activity of Borago officinalis on Fusarium sp and Alternaria sp.

de generar pérdidas millonarias en el sector agrícola. Es un sector creciente que representa el 11,9\% del territorio nacional (5 099744 ha). De este, el $40,2 \%$ se utiliza para cultivos como café, palma de aceite, caña de azúcar, entre otros, y un $20,3 \%$ se dedica a los cereales (DANE 2017). Adicionalmente, se encuentran los cultivos de musáceas como banano del subgrupo Cavendish, que ocupan un área de 561922 ha del territorio, donde el $11,27 \%$ del área es destinado para su producción y exportación y el otro $88,76 \%$ es destinado para el consumo interno (ICA 2019).

El interés generado por empresas exportadoras para ingresar en los mercados internacionales de productos provenientes de la actividad agrícola, ha promovido el incremento de los estándares de calidad que a la vez generan sobrecostos de producción, entre los cuales resalta el control de plagas y enfermedades. 
Tradicionalmente, el control de enfermedades de origen fúngico ha dependido del tratamiento con agroquímicos (Chávez y Aquino 2012). Los agroquímicos representan un riesgo para el ambiente y la salud humana, los cuales pueden llegar a ser cancerígenos; además su uso genera residuos que contaminan el suelo, el aire, los cuerpos de agua y en algunos casos, son perjudiciales para la biota responsable del control natural de plagas y patógenos potenciales (Abdel-Monaim et al. 2011, Rodríguez-Maturino et al. 2015, Tirumale y Wani 2018). Ante este problema, una de las posibles alternativas que permiten reducir las enfermedades en plantas causadas por hongos fitopatógenos es el uso de extractos vegetales, los cuales han demostrado tener efectos como controladores de ácaros, roedores, nematodos, bacterias, virus, hongos e insectos (Celis et al. 2009, Boadu et al. 2011). Además, poseen poca o ninguna toxicidad contra el ser humano y son rápidamente degradados en el suelo en comparación con los agroquímicos utilizados actualmente (Corato et al. 2010, Mahlo et al. 2010, Rodríguez-Maturino et al. 2015).

Para un país en el que los sistemas agrícolas representan una de las formas de uso del suelo más importantes, a su vez deberá ser parte de sus prioridades, la cual depende en parte, del buen mantenimiento y control biológico de fitopatógenos (Moreno-Velandia et al. 2018). Complementariamente, se debe considerar que Colombia posee entre 40000 y 45000 especies de plantas lo que lo convierte en el segundo país a nivel mundial de diversidad de especies de las cuales al menos 6000 poseen propiedades medicinales (Giraldo-Quintero et al. 2015), tradicionalmente es un país con una larga historia de uso de plantas como alimentos, medicina, vestuario y rituales ancestrales (Gómez-Fonnegra y VillaLondoño 2011).

Especies de plantas consideradas como malezas, tal como B. officinalis, son ampliamente utilizadas con fines medicinales y culinarios, entre los que resaltan como una fuente rica de ácido gamma linoleico, precursor de prostaglandinas antiinflamatorias; además, de poseer actividad antioxidante laxante, emoliente diurético entre otros (Galle et al. 1993, Ratz-Łyko et al. 2014, Fernandes et al. 2019). Diversos estudios sobre las propiedades fitoquímicas de $B$. officinalis también han identificado la presencia de actividad antimicrobiana frente a diversos patógenos de interés (Mhamdi et al. 2009, Arévalo 2009, Nieto-Navarro 2012, Basar et al. 2013, Miceli et al. 2014, Ávila 2016).

Algunos extractos naturales presentan actividad antifúngica por sus principios activos o "metabolitos secundarios", los cuales son compuestos químicos que suelen estar presentes en fuentes botánicas, además, no representan un peligro para la salud humana (Lock et al. 2016). Los metabolitos secundarios presentes pueden ser terpenoides, compuestos fenólicos, fenilpropanoides, estilbenos, alcaloides, saponinas, entre otros (Dixon 2001, Okwu y Nmamdi 2008). Algunos como los fenoles y flavonoides son responsables de actividad antimicrobiana, reportados principalmente contra Escherichia coli y Candida spp (Cushnie y Lamb 2005, Corato et al. 2010, Echavarría et al. 2016, Abu et al. 2017, Jasso de Rodríguez et al. 2019). En el caso de hongos se considera que la actividad antimicrobiana de los metabolitos secundarios, está relacionada con la inhibición de la germinación de los conidios por parte de los hongos o por la inactivación de la síntesis de aminoácidos esenciales (Cushnie y Lamb 2005, Pietarinen et al. 2006, Kappel et al. 2008, De Castro et al. 2010).

En la actualidad existen pocos datos publicados acerca de la actividad de B. officinalis sobre especies de hongos fitopatógenas, por lo cual el objetivo de este estudio fue evaluar in vitro la actividad antifúngica del extracto etanólico de hojas de Borraja (B. officinalis) sobre hongos fitopatógenos productores de micotoxinas que provocan daños graves a cultivos de frutas y verduras como Fusarium sp y Alternaria sp. Para lograr este objetivo, se identificaron metabolitos secundarios presentes en B. officinalis; además, se cuantificó el contenido de fenoles y flavonoides totales presentes en el extracto etanólico de hojas de B. officinalis. Además, 
Fusarium sp y Alternaria sp fueron caracterizados por estudios moleculares y bioinformáticas mediante la amplificación de la región ITS del ADN ribosomal y finalmente, se determinó el porcentaje de inhibición del crecimiento del extracto de las hojas de B. officinalis sobre los aislamientos previamente identificados mediante la prueba de crecimiento radial por técnica de difusión en agar.

\section{MATERIALES Y MÉTODOS}

Obtención del material vegetal. El material vegetal de la maleza conocida con el nombre de Borraja (B. officinalis) fue obtenido en noviembre de 2018 en Mendoza. Durante ese proceso se consideró que las plantas fueran ejemplares adultos y no presentaran signos de enfermedad aparente, como la presencia de pigmentos marrones, amarillos $\mathrm{u}$ oscuros en las hojas. Con el fin de corroborar la especie utilizada, 4 muestras de $B$. officinalis fueron prensadas, con el protocolo para la entrega de colecciones botánicas y depositadas en el herbario de la Universidad Nacional de Colombia con la utilización del servicio de identificación taxonómica para muestras botánicas para proporcionar la correcta clasificación.

Obtención del extracto. El extracto de las hojas de B. officinalis se obtuvo a partir de $1000 \mathrm{~g}$ de hojas frescas separadas manualmente del tallo. Estas fueron desinfectadas con hipoclorito de sodio $1 \% \mathrm{y}$, posteriormente, lavadas con agua destilada y secadas al aire durante 24 horas a temperatura ambiente; después, fueron trituradas con una picadora y sumergidas en etanol $98 \%$ en relación 1:2 en un recipiente de vidrio. Posteriormente, el recipiente fue envuelto en papel aluminio y se dejó en reposo durante 10 días. Después, el extracto fue filtrado y el material vegetal se colocó de nuevo en el recipiente de vidrio con etanol 98\% para reposar nuevamente durante 10 días. Este proceso se repitió en 3 ocasiones. Finalmente, el filtrado se secó en rota evaporador durante 3 horas a $40^{\circ} \mathrm{C}$ con una presión de 125 mbar. El secado final del extracto fue en cabina de extracción de gases durante 5 horas a $30^{\circ} \mathrm{C}$.

Identificación cualitativa y cuantificación de los metabolitos secundarios. Con el fin de determinar la composición general de metabolitos secundarios presentes en B. officinalis, se realizó un proceso fitoquímico propuesto por Lock (2016) (Figura 1). Para la fenoles se utilizó la prueba de cloruro férrico; para esteroles y metilesteroles, la de Salkowski; para esteroides y terpenos, la de Liberman-Buchard; para coumarinas, se utilizó la de hidróxido de sodio; para saponinas, la de espuma y para leucoantocianidinas, la de $\mathrm{HCl}$ concentrado (Robles et al. 2016, Navarrete et al. 2017). 


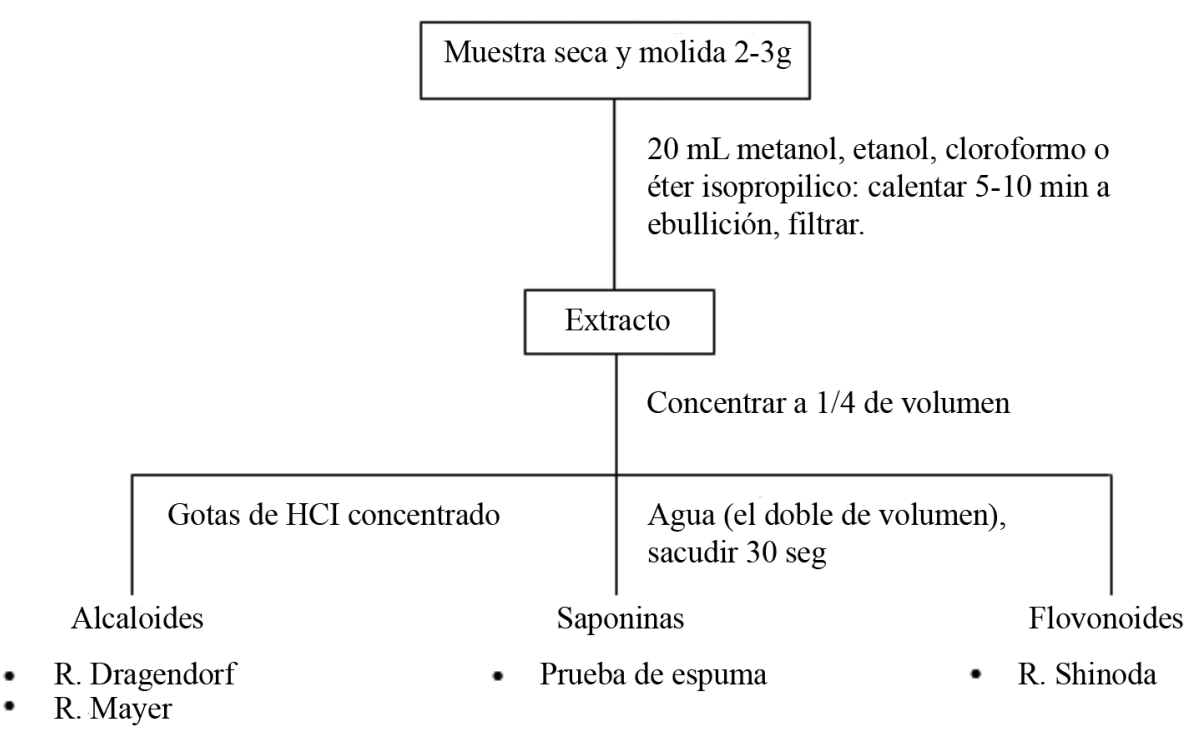

Figura 1. Identificación cualitativa de Alcaloides, Saponinas y Flavonoides, a partir de "Investigación Fitoquímica: Métodos en el estudio de productos naturales" (Lock 2016).

Cuantificación de polifenoles y flavonoides. Los fenoles y flavonoides son considerados los responsables de la actividad antimicrobiana en plantas (Kappel et al. 2008, De Castro et al. 2010), por lo cual se consideró importante su cuantificación. El contenido de total de polifenoles se determinó por el método Folin-Ciocalteau (Fo-Cio) y se siguió el método propuesto por Cicco et al. (2009). Se mezclaron $100 \mu \mathrm{L}$ de ácido gálico (reactivo analítico) con $200 \mu \mathrm{L}$ del reactivo Folin-Ciocalteau al 10\%, después de 4 minutos se agregaron $800 \mu \mathrm{L}$ de solución acuosa de $\mathrm{Na}_{2} \mathrm{CO}_{3}(700 \mathrm{mM})$. La mezcla se agitó y calentó en baño maría a $40^{\circ} \mathrm{C}$ durante 20 minutos, la curva estándar se preparó con el estándar acido gálico (15, 25, 40, 75, 100, 120 en mg.1 $\left.{ }^{-1}\right)$. Para determinar el contenido de fenoles totales, se expresó en miligramos equivalentes de ácido gálico (EAG) por gramo de extracto, la cuantificación de polifenoles se realizó por triplicado a $720 \mathrm{~nm}$ en espectrofotómetro (Thermo Scientific 840-210300).

Además, el contenido total de flavonoides se determinó mediante los métodos propuestos por Nabavi et al. (2008). Se mezclaron $100 \mu \mathrm{L}$ del estándar catequina (Qe) al $10 \%$ con $800 \mu \mathrm{L}$ de metanol, luego se adicionó $100 \mu \mathrm{L}$ de $\mathrm{AlCl}_{3}$ (10\%) junto con $100 \mu \mathrm{L}$ de acetato de sodio $(0,1 \mathrm{M})$, finalmente, se dejaron reposar durante 30 minutos a temperatura ambiente. La curva estándar se preparó al utilizar como estándar catequina $\left(15,25,35,50,75,100\right.$ y $\left.125 \mathrm{mg} \cdot \mathrm{l}^{-1}\right)$. El total de flavonoides se expresó en miligramos equivalentes de catequina (Qe) por gramo de extracto. La cuantificación de flavonoides se realizó por triplicado a $420 \mathrm{~nm}$ en espectrofotómetro.

Identificación molecular de los aislamientos de hongos. Con el fin de caracterizar molecularmente los aislamientos de Fusarium sp y Alternaria sp de un cepario de hongos de la Universidad Central donde fue realizado el estudio para posteriormente ser conservados en glicerina $15 \%$ a una temperatura de $-20^{\circ} \mathrm{C}$. Los aislados fueron reactivados mediante la siembra en superficie en el medio de cultivo papa, dextrosa-agar (PDA) e incubados a $27^{\circ} \mathrm{C}$ durante 72 horas. La extracción del ADN de los aislamientos 
se realizó con el kit de extracción Genomic DNA $^{\mathrm{TM}}$ Tissue MiniPrep (Zymo Research, Irvine, EEUU), se siguieron las instrucciones del fabricante y se verificó en gel de agarosa. Posteriormente se realizó una PCR para amplificar la región ITS del ADNr con los primers universales descritos por White et al. (1990). ITS1 (5'TCCGTAGGTGAACCTGCGG-’3) e ITS4 (5'TCCTCCGCTTATTGATATGC-3'). La mezcla para la amplificación se realizó en un volumen de $90 \mathrm{~mL}$ con 12,5 mL de 10X PCR buffer $\mathrm{MgCl}_{2}(1,5 \mathrm{Mm}), 1 \mathrm{~mL} \mathrm{MgCl}_{2}, 3,75 \mathrm{~mL}$ de dNTP'S, ITS1 e ITS4, 1,25 mL de Taq ADN polimerasa y $1 \mathrm{~mL}$ ADN el cual fue estandarizado a 10 ng. La amplificación se realizó en un termociclador (BIO-RAD C1000 thermal cycler) con un ciclo inicial de $94^{\circ} \mathrm{C}$ por 5 minutos, 35 ciclos a temperatura de desnaturalización de $94^{\circ} \mathrm{C}$ por 1 minuto, una temperatura de anillado de $56^{\circ} \mathrm{C}$ por 30 segundos, una temperatura de extensión de $72^{\circ} \mathrm{C}$ por 30 segundos y un ciclo final a $72^{\circ} \mathrm{C}$ por 7 minutos.

Asimismo, los productos de PCR fueron purificados con el uso del kit de purificación de Zymo Research, Irvine, EEUU. Fueron secuenciados mediante el método Sanger por servicio técnico en el SSIGMOL. La identificación de los aislamientos se determinó mediante el programa BLAST (Basic Local Alignment Search Tool) del NCBI, estos resultados se compraron con la base de datos RDP de Michigan State University con el programa Classifier Fungal ITS Warcup por medio de un porcentaje de similitud de $95 \%$.

Selección del vehículo de siembra. Varios fármacos y extractos experimentales no se disuelven en agua o soluciones salinas y se requiere de otros solventes, como detergentes o aceites vegetales, que sean inocuos a los organismos, este es el caso del Dimetilsulfóxido
(DMSO) y Tween 20 que son 2 reactivos comúnmente utilizados como vehículos por la industria farmacéutica (Castro et al. 1995, Sánchez-Recillas et al. 2020). Para la selección del vehículo, se evaluó la actividad antifúngica in vitro del extracto etanólico de las hojas de B. officinalis, mediante la prueba de crecimiento radial por técnica de difusión en agar. Para ello se utilizó como medio de cultivo PDA con el extracto etanólico disuelto en DMSO o en Tween 20, ambos al 5\% (Nieto Navarro 2012). Los trozos (6 mm de diámetro) de los aislamientos de Fusarium sp y Alternaria sp, de 7 días de crecimiento, fueron ubicados en el centro de la caja de Petri para luego ser incubados durante 9 días a $27^{\circ} \mathrm{C}$. Cada 3 días se realizó lectura del crecimiento radial del micelio y el proceso fue realizado por triplicado. Como controles negativos se utilizó DMSO al 5\% y Tween 20 al 5\% en Agar PDA sin de extracto vegetal y, como, control positivo se utilizó un antifúngico comercial, el cual contiene propamocarb- $\mathrm{HCl}+$ metalaxyl a una con-

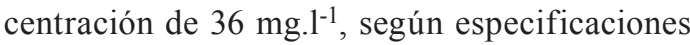
del fabricante.

Ensayos de actividad antifúngica del extracto. La actividad antifúngica del extracto de las hojas de B. officinalis se llevó a cabo con DMSO al 5\% como vehículo y por la técnica de difusión en agar, con concentraciones de 6,8 , $10,12,13,14,15$ y $16 \mathrm{mg} . \mathrm{l}^{-1}$ de extracto vegetal (Nieto Navarro 2012). Para el análisis de los resultados, se calculó el porcentaje de crecimiento micelial o radial respecto al control del medio inoculado con los hongos, se consideró como el $100 \%$ del crecimiento radial o $0 \%$ de inhibición del crecimiento micelial mediante la siguiente ecuación (Ezziyyani et al. 2004, Marquez-Vizcaino et al. 2007, Saúl et al. 2011, Bautista et al. 2016).

$$
\% \text { inhibición micelial o radial }=\frac{\text { Control negativo }- \text { Tratamiento }}{\text { Control negativo }} \times 100
$$


Análisis estadístico. Para evaluar el porcentaje de inhibición del crecimiento Fusarium sp y Alternaria sp frente a $B$. officinalis, todas las medidas fueron tomadas por triplicado y expresadas como el valor \pm la desviación estándar. Además, los datos fueron analizados mediante un análisis de varianza (ANOVA). De continuo, se comprobaron los supuestos de normalidad y homoscedasticidad seguido de una prueba de comparación múltiple de Tukey con el uso de la herramienta IBM spss statistics v25 2017.

\section{RESULTADOS Y DISCUSIÓN}

Identificación del material vegetal. El material vegetal fue identificado en el laboratorio según la descripción de Galle et al. (1993), De Smet (1993) y Abu et al. (2017) como Borago officinalis (Figura 2) donde se presenta tallo ramificado, presencia de pubescencia por toda la planta hasta las hojas. Se identificaron hojas alternas, anchas que decrecen en tamaño hacia el ápice de la rama; las hojas basales son pecioladas, ovales, las caulinares, sésiles y lanceoladas. Por su parte las flores que tienen forma de estrella de color azul, con estambres negros (Simpson 1993).

\section{A}

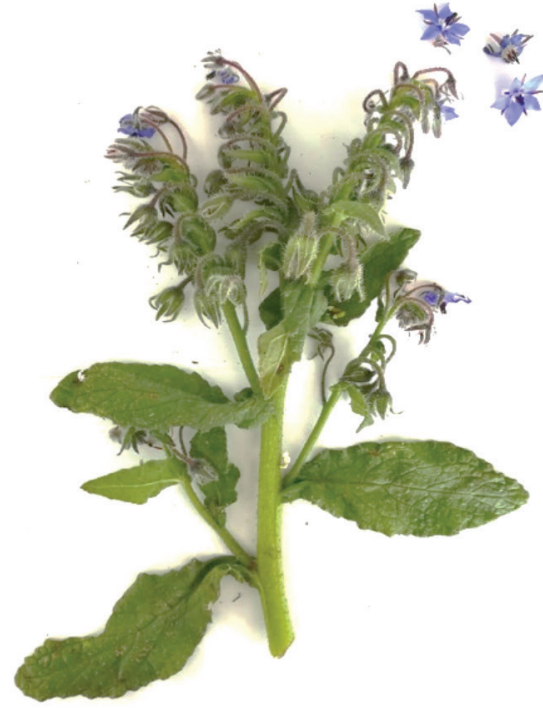

B

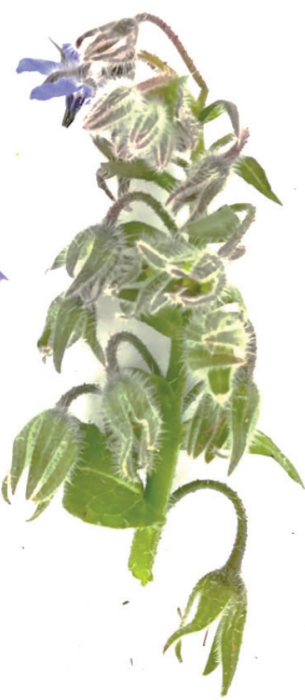

Figura 2. Hojas y flores de Borago officinalis. A) Tallo ramificado, hojas alternas, anchas que decrecen hacia el ápice de la planta. B) Flores de B. officinalis en forma de estrella de color azul, con estambres negros.

Además, se utilizó el servicio de estudio taxonómico para verificar la identificación de $B$. officinalis realizado por el Herbario Nacional de Colombia de la Universidad Nacional de Colombia, donde se obtuvo una verificación de Borago officinalis con designación de muestra BO1 y número de colección 612220 .
Identificación cualitativa de metabolitos secundarios. De acuerdo con los protocolos establecidos durante los ensayos cualitativos preliminares, se identificó la presencia de alcaloides, flavonoides, fenoles y saponinas; además, la presencia de esteroles y metilesteroles, esteroides y terpenos, coumarinas y leucoantocianidinas que fue negativa (Tabla 1). Los resultados 
coincidieron con los obtenidos por Echavarría et al. (2016) quienes reportan resultados similares a excepción de polifenoles; por otra parte, Leos (2010) reportó la ausencia de flavonoides al aplicar la prueba de $\mathrm{H}_{2} \mathrm{SO}_{4}$. Otras investigaciones reportaron, de igual manera, la ausencia de compuestos como esteroles, esteroides y terpenos (Mhamdi et al. 2009, Abu et al. 2017, Saadatian et al. 2017). La presencia de compuestos como los fenoles y flavonoides sugiere que $B$. officinalis puede presentar distintas propiedades entre las que destacan la capacidad antioxidante, antimicrobiana y antifúngica (Reddy et al. 2007, Siva et al. 2008, Robles et al. 2016, Carvalho et al. 2018).

Tabla 1. Identificación de metabolitos secundarios en el extracto de las hojas de B. officinalis.

\begin{tabular}{lc}
\hline Metabolitos & Hojas de B. officinalis \\
\hline Alcaloides & + \\
Flavonoides & + \\
Fenoles & + \\
Esteroles y Metilesteroles & - \\
Esteroides y Terpenos & - \\
Coumarinas & - \\
Saponinas & + \\
Leucoantocianidinas & - \\
\hline
\end{tabular}

Presencia $=+$

Ausencia $=$ -

Cuantificación de polifenoles y flavonoides. El contenido total de polifenoles de las hojas de $B$. officinalis fue de $19,08 \pm 0,01$ $\left(\mathrm{r}^{2}=0,97\right)$ reportado en miligramos equivalentes de ácido gálico (EAG) por gramo de extracto. Por otro lado, el contenido de flavonoides de las hojas de $B$. officinalis fue de 28,12 $\pm 0,06$ $\left(\mathrm{r}^{2}=0,99\right)$, reportado como miligramos equivalentes de catequina (Qe) por gramo de extracto. El contenido total de polifenoles de las hojas de $B$. officinalis concuerda con los resultados obtenidos por Segovia et al. (2014), en el que sus resultados variaron de 19,16 a $27,49 \mathrm{mg}$ equivalentes de ácido gálico. $\mathrm{g}^{-1}$ de extracto, en las hojas de B. officinalis a partir de un extracto etanólico; sin embargo, el contenido total de polifenoles es significativamente menor en comparación con los reportados por Zemmouri et al. (2014), quienes reportaron un contenido total de polifenoles presentes en hojas de $B$. officinalis a partir de un extracto etanólico de $94,09 \pm 1,72 \mathrm{mg}$ equivalentes de ácido gálico.g ${ }^{-1}$ de extracto.

El contenido de polifenoles totales concuerda con el registrado para varias plantas aromáticas y de uso medicinal (Zheng y Wang 2007). Además, el contenido de flavonoides totales difiere de los resultados obtenidos por Zemmouri et al. (2014) en su estudio de la composición química y antioxidante de $B$. officinalis, pues se obtuvo como resultado $37,6 \pm 3,9$ miligramos equivalentes de catequina $(\mathrm{Q} e) \cdot \mathrm{g}^{-1}$ de extracto. La presencia de polifenoles y flavonoides en este estudio podrían indicar acción antifungica (De Castro et al. 2010, Leon Duran y Mancheno Cárdenas 2021).

Identificacion molecular de los aislamientos de hongos. Las secuenciaciones de regiones ribosomales con marcadores ITS sugieren que los aislamientos, identificados previamente por su morfología pueden ser Fusarium sp y Alternaria sp. La amplificación de la banda para los primers utilizados fue la esperada (500 pb) según las secuenciaciones de Villavicencio (2013), Vanegas Berrouet et al. (2014) y Salazar (2016), para $F$. oxyspoprum fue de $550 \mathrm{pb}$ mientras que para Alternaria sp fue $580 \mathrm{pb}$.

El análisis de la secuencia ITS realizado con la herramienta BLASTn del NCBI mostró una identidad de la secuencia del 99,83\% para Fusarium sp y la información fue depositada en el GenBank del NCBI con el número de acceso KP942940.1. La secuencia para Alternaria sp mostró una identidad del $99 \%$ con varias especies como Alternaria arborescens y Alternaria alternata (números de acceso GenBank: MK460794.1, JQ910882.1, MK461082.1, MN044802.1), por lo que no se logró especificar claramente la especie y, por tanto, fue denominada Alternaria sp. 
Con el fin de constatar los resultados señalados, las secuencias se compararon con la base de datos RDP de Michigan State University, mediante el programa Classifier Fungal ITS Warcup, el cual mostró resultados similares para ambos casos, que sugieren la presencia de $F$. oxysporum con un umbral de confianza del 95\%; mientras que Alternaria sp obtuvo 56\% de identidad con Alternaria alternata con un umbral de confianza del 95\%, sin embargo, es definida como Alternaria_no identificada. Según los resultados, se toma la decisión de no atribuir ninguna especie para el caso de Alternaria sp. No obstante, la secuenciación de la región ribosomal con marcadores ITS puede no ser concluyente para la correcta identificación molecular de los aislamientos de Fusarium sp y
Alternaria sp, ya que debido a la gran cantidad de polimorfismo que existe entre especies estrechamente relacionadas, se recomienda el uso de más primers como TEF-1 $\alpha$ o RPB2 (Geiser et al. 2004, Salazar-González et al. 2016, RangelCastillo et al. 2017), razón por la cual se decidió no atribuir ninguna especie para los aislamientos secuenciados.

Selección del vehículo de siembra. El crecimiento radial de Fusarium sp y Alternaria sp se afectó de manera negativa por el extracto de $B$. officinalis mediante los vehículos DMSO al 5\% y Tween 20 al 5\%. Sin embargo, el extracto de B. officinalis presentó mayor porcentaje de inhibición para los 2 aislamientos evaluados con DMSO-5\% (Figura 3).

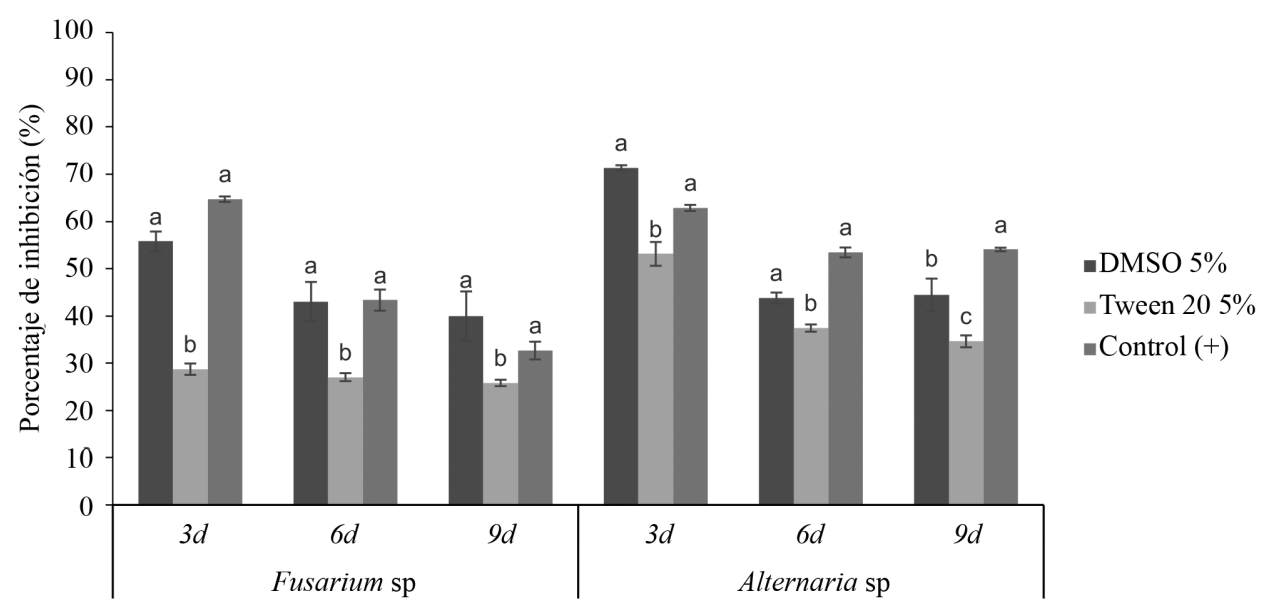

Figura 3. Efecto antifúngico del extracto de las hojas de B. officinalis sobre Fusarium sp y Alternaria sp después de 3, 6 y 9 días mediante DMSO 5\% y Tween-20 5\%.

En el caso de Fusarium sp, los tratamientos se dividieron en 2 grupos estadísticamente diferentes (ANOVA $\mathrm{p}<0,05$ ) en los 3 primeros días. El primer grupo incluyó los ensayos realizados con DMSO-5\% y el control $(+)$ y el segundo grupo incluyó los ensayos con Tween $20-5 \%$. Los tratamientos que conformaron el primer grupo presentaron mayor porcentaje de inhibición donde el control (+) fue el tratamiento más efectivo frente a Fusarium sp $(64,7 \pm 0,5 \%)$, seguido por el extracto vegetal disuelto en el

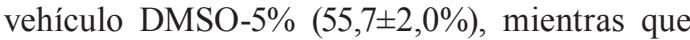
el segundo grupo conformado por el extracto vegetal disuelto en Tween-20 al 5\% presentó un porcentaje de inhibición significativamente menor $(28,7 \pm 1,2 \%)$. 
En la Figura 3, se observa que la inhibición de B. officinalis sobre Fusarium sp, disminuye a través del tiempo (6 y 9 días), ya que es el extracto disuelto en DMSO-5\% el tratamiento más efectivo frente a Fusarium sp $(40,0 \pm 5,1 \%)$ al final del experimento.

Para el caso de Alternaria sp se observó que el extracto de las hojas de B. officinalis inhibió el crecimiento en mayor porcentaje con respecto al Fusarium sp (Figura 3). Los resultados se dividieron en 2 grupos estadísticamente diferentes (ANOVA $\mathrm{p}<0,05$ ). El primer grupo (DMSO-5\% y control $(+)$ ) presentó mayor porcentaje de inhibición donde el control $(+)$ fue el tratamiento más efectivo frente a Alternaria sp $(71,3 \pm 0,5 \%)$ seguido por el extracto disuelto en DMSO-5\% $(62,8 \pm 0,6 \%)$. El segundo grupo conformado por Tween $20-5 \%$ presentó un porcentaje de inhibición menor $(53,1 \pm 2,5 \%)$.

Al igual que para el caso de Fusarium sp, la efectividad del extracto de las hojas de $B$. officinalis sobre Alternaria sp disminuyó a través del tiempo. Es importante resaltar que por 9 días, se conformaron 3 grupos, el primero formado por el control $(+)$, el segundo por DMSO-5\% y tercero por Tween 20 al 5\%; donde el control $(+)$ fue el tratamiento más efectivo frente a Alternaria sp (53,4 $\pm 0,3 \%)$.

Vehículos de dilución como DMSO funcionan como potenciadores de los extractos vegetales, ya que incrementan la penetración de sus principios activos, además, la asociación de extractos vegetales de origen acuosos, etanólicos y metanólicos aumentó la efectividad, en este caso el porcentaje de inhibición del crecimiento radial para los 2 aislamientos evaluados (Figura 3) (Ravindran et al. 2011, Bobadilla Alvarez y Reyes Castro 2020).

Algunos vehículos, como Tween 20, pueden disminuir la actividad locomotora del extracto al impedir la correcta dilución en el medio inoculado, lo cual reduce su eficiencia (Castro et al. 1995). Recursos como Tween 20 y Tween 80 pueden inactivar compuestos fenólicos que han sido reportados como los encargados de la actividad antimicrobiana presente en los extractos de plantas (Dixon 2001, Akhila 2009). La selección previa del medio de dilución del extracto es importante, ya que estos pueden presentar efecto de inhibición de la actividad biológica del extracto así como efectos tóxicos sobre el organismo evaluado (Jaeschke et al. 2006, Ravindran et al. 2011).

Aunque DMSO-5\% como agente fue más eficiente, DMOS-5\% y Tween $20-5 \%$ fueron efectivos frente a Fusarium sp y Alternaria sp, ya que presentaron un porcentaje de inhibición $\geq$ $20 \%$ al cabo de 9 días (Marquez-Vizcaino et al. 2007). Según los resultados observados, se seleccionó como recurso para los ensayos de actividad DMSO-5\% pues presentó mayor efectividad sobre la inhibición del crecimiento de Fusarium sp y Alternaria sp.

Ensayos de actividad antifúngica del extracto etanólico. Los ensayos de la actividad antifúngica del extracto etanólico de las hojas de B. officinalis se realizaron con diferentes concentraciones de extracto con DMSO-5\% como agente, para determinar la concentración más efectiva a través del tiempo (3, 6 y 9 días) (Figura 4). 


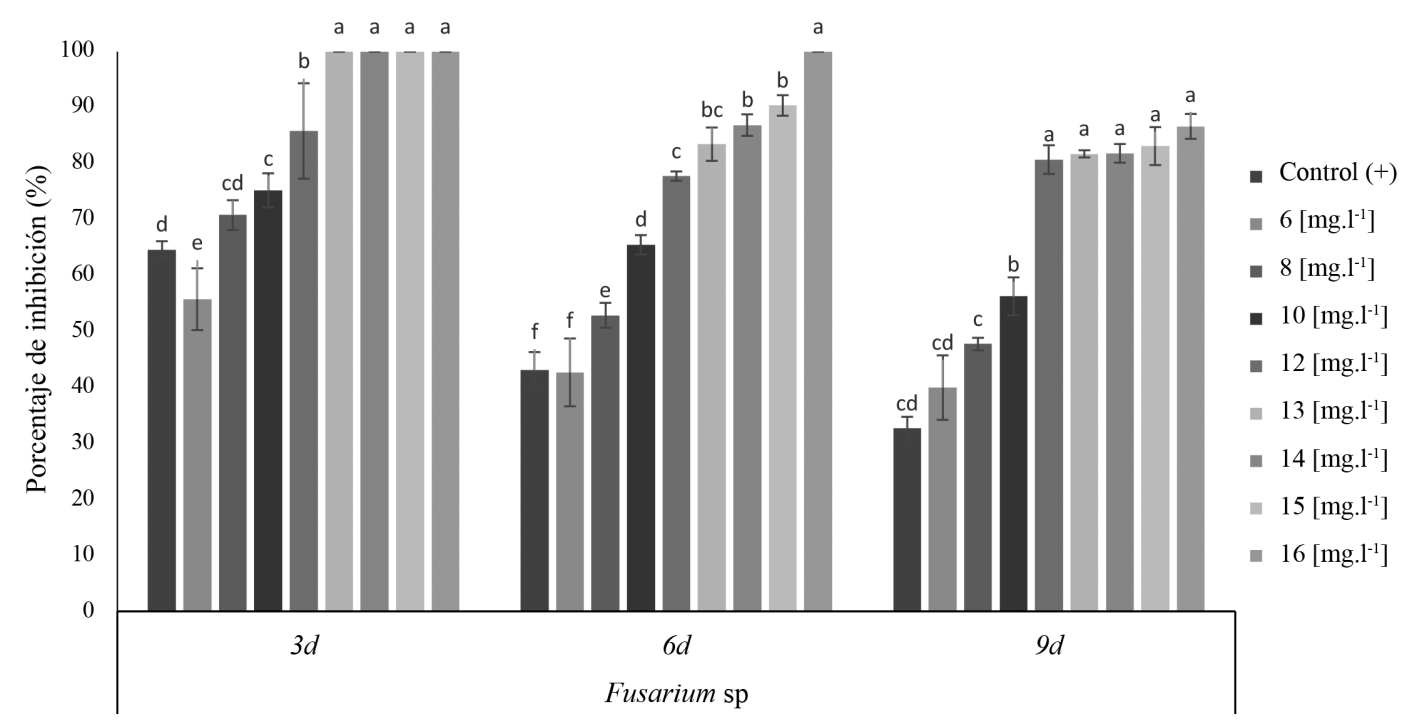

Figura 4. Efecto antifúngico de diferentes dosis del extracto de las hojas de B.officinalis sobre Fusarium sp después de 3, 6 y 9 días.

Para el caso de Fusarium sp, los tratamientos se dividieron en 6 grupos estadísticamente diferentes (ANOVA $\mathrm{p}<0,05$ ) y al cabo de 3 días, se observaron los que presentaron mayor porcentaje de inhibición del crecimiento. El grupo conformado por los tratamientos $13,14,15$ y 16 mg. $\mathrm{l}^{-1}$ mostró un porcentaje de inhibición de $100 \%$. Adicionalmente, tratamientos con $12 \mathrm{mg} . \mathrm{l}^{-1} \mathrm{y}$ $10 \mathrm{mg} .1^{-1}$ presentaron un porcentaje de inhibición de $85,4 \pm 8,5 \%$ y $75,2 \pm 3,0 \%$, respectivamente (Figura 4). La tendencia de disminución de la inhibición del crecimiento se observó conforme se redujo la concentración del extracto, pues fue el último grupo conformado por el tratamiento con concentración de $6 \mathrm{mg} . \mathrm{l}^{-1}$ y mostró menor inhibición del crecimiento (39,9 $\pm 5,7 \%)$.

Al cabo de 6 días los tratamientos se dividieron en 7 grupos estadísticamente diferentes (ANOVA $\mathrm{p}<0,05$ ). El primer grupo conformado por $16 \mathrm{mg} . \mathrm{l}^{-1}$ fue el único que presentó un porcentaje de inhibición de $100 \%$. También se observó que la inhibición de B. officinalis sobre Fusarium sp disminuyó a través del tiempo (6 y 9 días), donde el tratamiento de $16 \mathrm{mg} \cdot \mathrm{l}^{-1}$ fue el más efectivo frente a Fusarium sp $(86,6 \pm 2,2 \%)$ al final del experimento (Figura 5). 

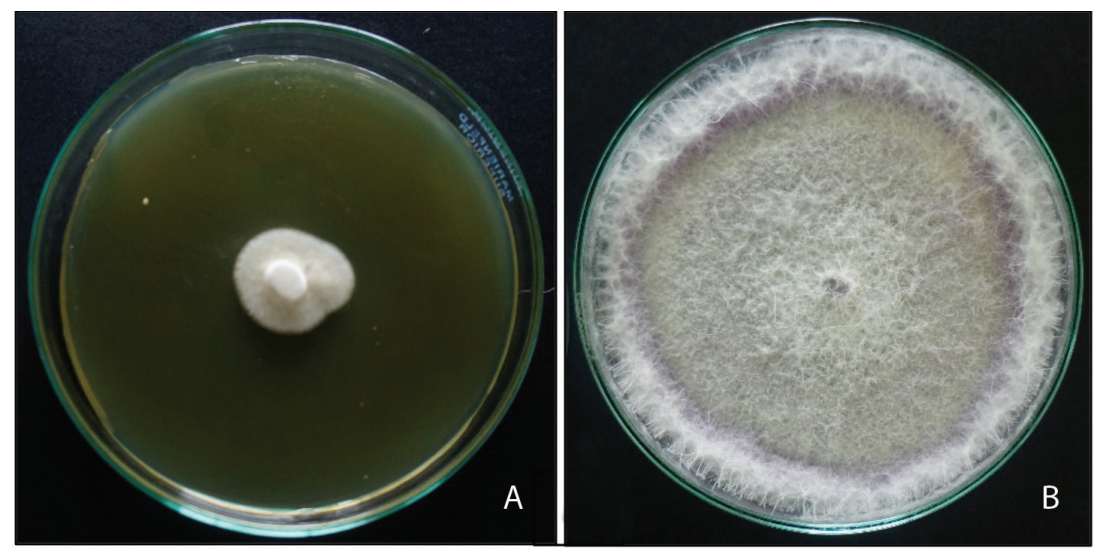

Figura 5. Actividad de Borago officinalis contra Fusarium sp. A) Fusarium sp al cabo de 9 días de tratamiento a una concentración de 16 mg.1 $\mathrm{l}^{-1}$. B) Control (-) Fusarium sp al cabo de 9 días.

En contraste con los resultados obtenidos por Nieto-Navarro (2012), quien evaluó el efecto antifúngico de varias plantas medicinales entre ellas $B$. officinalis con concentraciones similares del extracto sobre Fusarium sp, reportó la ausencia de actividad antifúngica. Sin embargo, no reportó uso de un vehículo de dilución del extracto. Castro et al. (1995), Bobadilla-Alvarez y Reyes-Castro (2020) corroboran la importancia en la selección de un medio para ensayos de actividad de extractos vegetales el cual podría mejorar la actividad biológica. Sin embargo, Fusarium sp es un fitopatógeno multiresistente y los extractos vegetales con capacidad antifungica con frecuencia están limitados por el desarrollo de resistencia enzimática o por procesos de sustitución genética.
Para el caso de Alternaria sp los tratamientos se dividieron en 3 grupos estadísticamente diferentes (ANOVA $\mathrm{p}<0,05$ ). Después de 3 días, se observó que presentaron mayor porcentaje de inhibición del crecimiento. El primer grupo se conformó con los tratamientos de mayor concentración $\left(12,13,14,15\right.$ y $\left.16 \mathrm{mg} . \mathrm{l}^{-1}\right)$ mediante un porcentaje de inhibición del $100 \%$. El segundo grupo se conformó por tratamientos de 8 y $10 \mathrm{mg} . \mathrm{l}^{-1}$ de concentración que presentaron un porcentaje de inhibición de $89,5 \pm 2,2 \%$ y $85,6 \pm 9,0 \%$, respectivamente. El tercer grupo fue conformado con una concentración de $6 \mathrm{mg} . \mathrm{l}^{-1}$ y el control $(+)$ que presentaron $71,3 \pm 2,5 \%$ y $62,8 \pm 2,5 \%$ (Figura 6). 


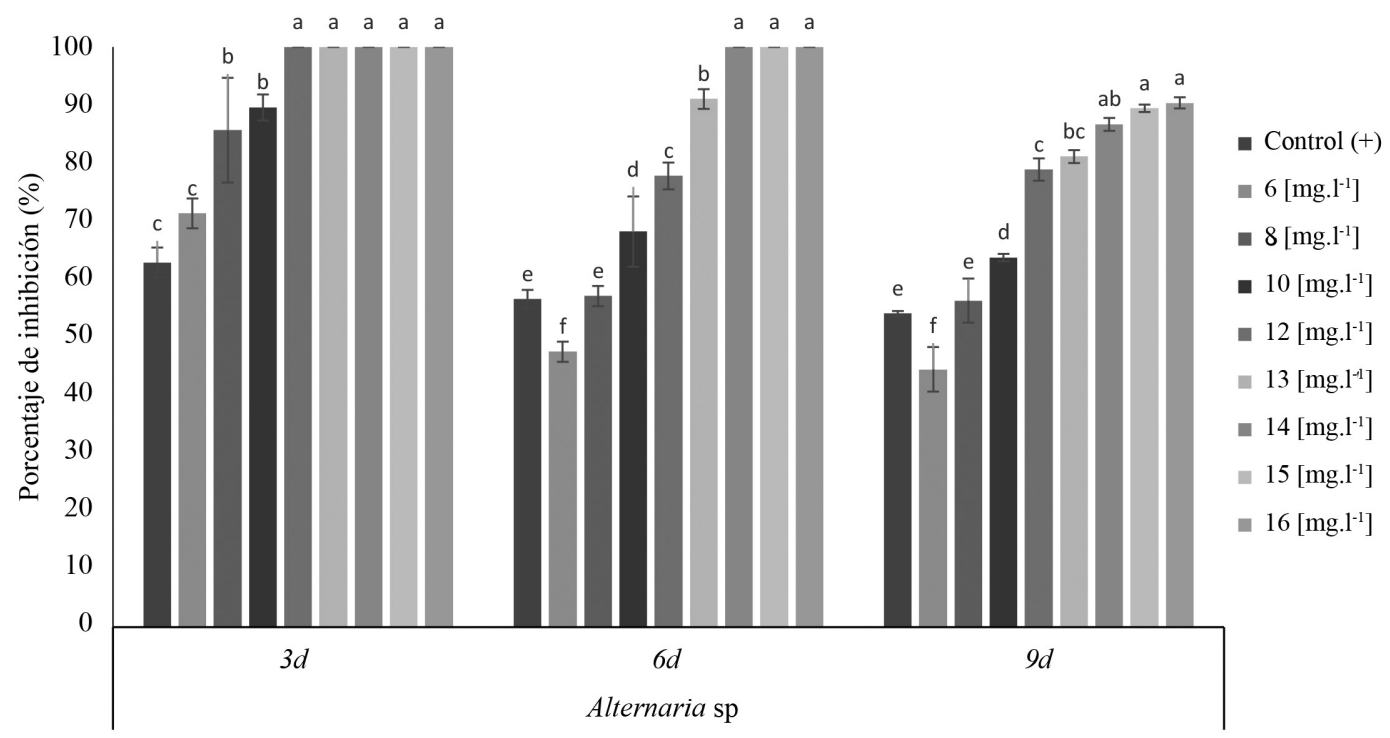

Figura 6. Efecto antifúngico de diferentes dosis del extracto de las hojas de B.officinalis sobre Alternaria sp después de 3, 6 y 9 días.

Al igual que para el caso de Fusarium sp, la inhibición de $B$. officinalis sobre Alternaria sp disminuyó a través del tiempo (6 y 9 días). Después de 6 días, los tratamientos se dividieron en 6 grupos estadísticamente diferentes, donde el primer grupo fue conformado por los tratamientos de 14,15 y 16 mg..$^{-1}$ los cuales presentaron más efectividad frente a Alternaria sp (100\%). El tratamiento más efectivo al final de 9 días fue $16 \mathrm{mg} . \mathrm{l}^{-1}$ frente a Alternaria sp $(90,3 \pm 0,96 \%)$ (Figura 7).
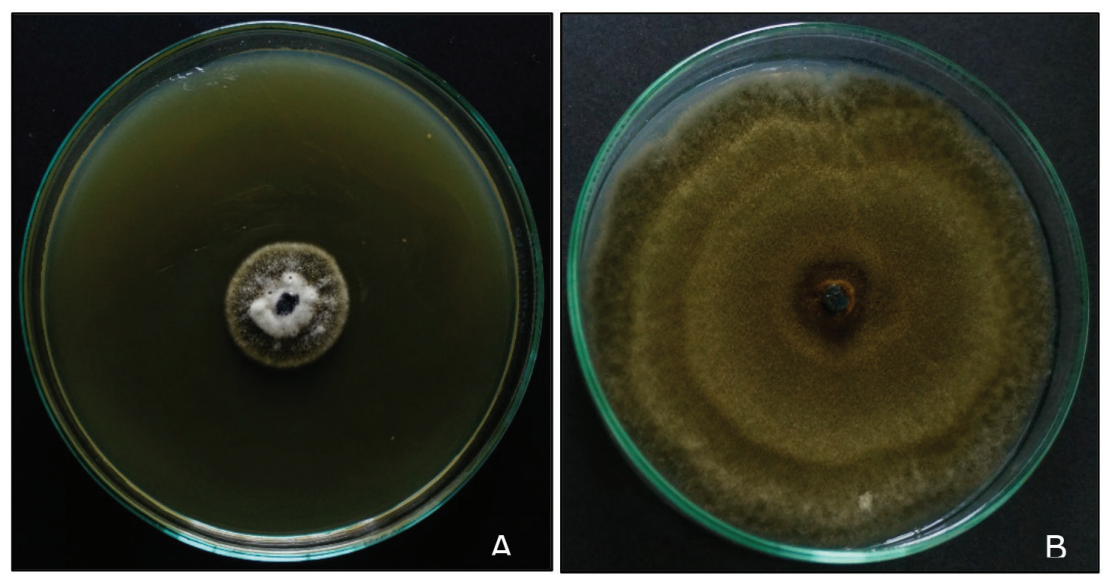

Figura 7. Actividad de Borago officinalis contra Alternaria. sp. A) Alternaria sp al cabo de 9 días de tratamiento a una concentración de $16 \mathrm{mg} . \mathrm{l}^{-1}$. B) Control (-) Alternaria sp al cabo de 9 días. 
Se evidenció un contraste con los resultados obtenidos por Arévalo (2009), quien solo reportó actividad antifungica frente a Alternaria sp. Khafari et al. (2014) evaluaron el efecto de $B$. officinalis sobre Alternaria sp en una concentración de $5 \mathrm{mg}$ diluidos sobre discos de papel, ya que reportaron la ausencia de actividad antifúngica, a diferencia de los obtenidos en el presente estudio, que fue la concentración mínima evaluada de $6 \mathrm{mg} .1^{-1}$ con el uso de la técnica de dilución en agar con vehículo de dilución (DMSO-5\%).

La inhibición observada se considera altamente efectiva de acuerdo con Marquez-Vizcaino et al. (2007) al presentar un porcentaje de $\geq 20 \%$. Sin embargo, el extracto de $B$. officinalis mostró la presencia de actividad fungistática, ya que el crecimiento de Fusarium sp y Alternaria sp fue reactivado al cabo de 3 días para la mayoría de las concentraciones evaluadas, excepto $16 \mathrm{mg}^{-1}{ }^{-1}$ donde el crecimiento fue reactivado después 6 días (Soylu et al. 2010, Moreno 2011).

Los resultados obtenidos pueden relacionarse con la presencia de compuestos fenólicos por parte de B. officinalis, comúnmente relacionados con la actividad antimicrobiana de los extractos vegetales (Gatto et al. 2011, RodriguezMaturino et al. 2015, Fabrikov et al. 2019). La presencia de compuestos fenólicos en el extracto de $B$. officinalis corroboraron la presencia de la actividad antifúngica que actúa como repelente, además de inhibir la acción enzimática por oxidación de las topoisomerasas implicadas en procesos de transcripción y reparación del ADN (Lizcano González 2007, De Castro et al. 2010, Azuero et al. 2016, Mesa et al. 2019). Además, atacan la membrana citoplasmática del patógeno, lo cual afecta la capacidad selectiva y permite el escape de componentes intracelulares (Nychas 1995).

La pérdida de actividad fungicida del extracto de las hojas de B.officinalis sobre Fusarium sp y Alternaria sp respondió a sus mecanismos de resistencia entre los que destaca la resistencia metabólica por parte de especies patógenas mediante la acción enzimática. Incluso para el caso de hongos y malezas son capaces de reducir la sensibilidad en el sitio de acción de manera que antifúngico no pueda fijarse al sitio de acción, al inhibir o reducir significativamente su efectividad (Hernández 2012).

Existe un riesgo intrínseco en la aplicación de las dosis de los extractos vegetales o fungicidas, además, de la subdivisión de las mismas, ya que se ejerce mayor presión de selección, lo cual favorecería la supervivencia de una parte de la población de hongos menos sensibles a los principios activos aplicados, en ese sentido el fungicida ejerce presión sobre el hongo y mata solo a la población sensible (Hobbelen et al. 2011, Gressel 2011, Hollomon 2012, Grimmer et al. 2015, Carmona y Sautua 2017).

Eidi et al. (2014) reportan la presencia de actividad antifúngica de $B$. officinalis en 3 especies de hongos fitopatógenos del género de Aspergillus (A. fumigatus, A. niger y A. flavus), resultados que corroboran el potencial antifúngico por parte de B. officinalis. Gatto et al. (2011) también reportaron la presencia de actividad antifúngica de B. officinalis sobre Botrytis cinérea, Monilia laxa, Aspergillus niger, Aspergillus carbonarius, entre otros.

\section{CONCLUSIONES}

El extracto etanólico de las hojas de Borago officinalis expuso un alto contenido de fenoles y flavonoides totales que hacen de esta planta una especie promisoria por los beneficios que podría ofrecer en el control biológico de hongos fitopatógenos.

El extracto etanólico de las hojas de Borago officinalis fue efectivo en el control in vitro de Fusarium sp y Alternaria sp, con resultados similares al fungicida comercial propamocarb$\mathrm{HCl}+$ metalaxyl, el cual es de uso común.

Se demostró la actividad antifúngica del extracto etanólico de las hojas de Borago officinalis, lo que sugiere que su aplicación puede ser una alternativa para su empleo en el manejo agroecológico de los hongos fitopatógenos.

La investigación reportó la evaluación del extracto etanólico de Borago officinalis 
planta considerada como maleza en regiones del país no obstante, se evidencia el valor agregado que puede ofrecer dentro de la cadena agroproductiva.

\section{RECOMENDACIONES}

Se recomienda realizar el fraccionamiento y obtención estructural de los metabolitos secundarios en Borago officinalis que presenten actividad antifúngica sobre Fusarium sp y Alternaria sp.

Asimismo, evaluar la actividad antifúngica de $B$. officinalis sobre otras especies de hongos fitopatógenos. Es recomendable establecer la concentración mínima inhibitoria del extracto y realizar ensayos en aplicaciones sucesivas con el fin de evitar que los hongos creen resistencia a los metabolitos secundarios presentes en el extracto.

\section{AGRADECIMIENTOS}

Las personas autoras agradecen a la Facultad de Ingeniería y Ciencias Básicas de la Universidad Central donde fue llevado a cabo el estudio. También a María Camila Escobar, Gladys Cardona, Marcela Carrillo, William Quintero del instituto SINCHI y a Jorge Robles de la Pontificia Universidad Javeriana por su ayuda y orientación en este trabajo.

\section{LITERATURA CITADA}

Abdel-Monaim, MF; Abo-Elyousr, KAM; Morsy, KM. 2011. Effectiveness of plant extracts on suppression of damping-off and wilt diseases of lupine (Lupinus termis Forsik). Crop Protection 30(2):185-191. DOI: https://doi.org/10.1016/j.cropro.2010.09.016.

Abu, M; Nyeem, B; Haque, MS; Hoque, MA; Islam, MM; Islam, S. 2017. Phytoconstituents and pharmacological activity of Gauzaban ( Borago officinalis Linn ): A Review 2(1):148-152. DOI: https://doi.org/2017.

Agrios, G. 2005. Plant pathology: 5 ed. s.l., Academic Press. 922 p.
Akhila, A. 2009. Essential Oil-Bearing Grasses: The genus Cymbopogon. Akhila, A (ed.). Boca Raton, FL, USA, CRC Pess. 131 p.

Arévalo, J. 2009. Obtención de extractos vegetales con actividad biocontroladora ante hongos fitopatógenos. Cuenca, Ecuador, Universidad del Azuay Facultad de Ciencia y Tecnología. 55 p.

Ávila, JJ. 2016. Efecto Antifúngico de seis extractos vegetales sobre el hongo Mycosphaerella sp en el cultivo de banano. s.l., Universidad Técnica de Machala. 29 p.

Azuero, A; Jaramillo Jaramillo, C; San Martin, D; D’Armas Regnault, H. 2016. Análisis del efecto antimicrobiano de doce plantas medicinales de uso ancestral en Ecuador / Analysis of antimicrobial effect of twelve medicinal plants of ancient use in Ecuador. Ciencia Unemi 9(20):11. DOI: https://doi.org/10.29076/issn.25287737vo19iss20.2016pp11-18p.

Basar, SN; Rani, S; Farah, SA; Zaman, R. 2013. Review on Borage Officinalis: A Wonder Herb. International Journal of Biological \& Pharmaceutical Research 4(8):582-587.

Bautista, M; Cristóbal, J; Tun, J; Reyes, A. 2016. Actividad in vitro de Bacillus spp. en la inhibición de crecimiento micelial de Fusarium equiseti y Fusarium solani aislado de chile habanero (Capsicum chinense Jacq.). Agronciencia 62(08):1123-1135.

Boadu, KO; Tulashie, SK; Anang, MA; Kpan, JD. 2011. Production of natural insecticide from Neem leaves (Azadirachta indica). Asian Journal of Plant Science and Research 1(4):33-38.

Bobadilla-Alvarez, M; Reyes-Castro, S. 2020. Efecto tóxico de los extractos de semillas de Annona muricata potenciados con dimetilsulfóxido sobre larvas IV y pupas de Aedes aegypt. Revista Peruana de Biología 27(2):215-224. DOI: https://doi.org/doi: http://dx.doi. org/10.15381/rpb.v27i2.17877.

Carmona, M; Sautua, F. 2017. La problemática de la resistencia de hongos a fungicidas. Causas y efectos en cultivos extensivos (en línea). Revista de la Facultad de Agronomía UBA 37(1):1-19. Consultado 19 set. 2019. Disponible en http://ri.agro.uba.ar/files/ download/revista/agronomiayambiente/2017carmon amarcelo.pdf

Carvalho, RS; Carollo, CA; de Magalhães, JC; Palumbo, JMC; Boaretto, AG; Nunes e Sá, IC; Ferraz, AC; Lima, WG; de Siqueira, JM; Ferreira, JMS. 2018. Antibacterial and antifungal activities of phenolic compound-enriched ethyl acetate fraction from Cochlospermum regium (mart. Et. Schr.) Pilger roots: Mechanisms of action and synergism with tannin and gallic acid. South African Journal of Botany 114:181-187. DOI: https://doi.org/10.1016/j. sajb.2017.11.010. 
Castro, CA; Hogan, JB; Benson, KA; Shehata, CW; Landauer, MR. 1995. Behavioral effects of vehicles: DMSO, ethanol, Tween-20, Tween-80, and emulphor-620. Pharmacology, Biochemistry and Behavior 50(4):521-526. DOI: https://doi. org/10.1016/0091-3057(94)00331-9.

Celis, A; Mendoza, C; Pachón1, ME. 2009. Review: Plant Extracts Used As Biocontrol in Management of Plagues, Diseases and Weeds. Temas Agrarios 14(1):5-16.

Chávez, AR; Aquino, AS. 2012. Control de los hongos del suelo Rhizoctonia sp., Fusarium sp. y Sclerotium sp. con extractos vegetales. Investigación Agraria 17(6):478-485.

Cicco, N; Lanorte, MT; Paraggio, M; Viggiano, M; Lattanzio, V. 2009. A reproducible, rapid and inexpensive Folin-Ciocalteu micro-method in determining phenolics of plant methanol extracts. Microchemical Journal 91(1):107-110. DOI: https://doi.org/10.1016/j. microc.2008.08.011.

Corato, U De; Maccioni, O; Trupo, M; Di Sanzo, G. 2010. Use of essential oil of Laurus nobilis obtained by means of a supercritical carbon dioxide technique against post harvest spoilage fungi. Crop Protection 29(2):142-147. DOI: https://doi.org/10.1016/j. cropro.2009.10.012.

Cushnie, TPT; Lamb, AJ. 2005. Antimicrobial activity of flavonoids. International Journal of Antimicrobial Agents 26(5):343-356. DOI: https://doi.org/10.1016/j. ijantimicag.2005.09.002.

DANE. 2017. Boletín Técnico Encuesta (en línea). Encuesta Nacional Agropecuaria:1-31. Consultado 08 oct. 2019. Disponible en https://www.dane.gov.co/ files/investigaciones/agropecuario/enda/ena/2017/ boletin_ena_2017.pdf

De Castro, HG; de Moura Perini, VB; dos Santos, GR; Leal, TCAB. 2010. Evaluation of content and composition of the essential oil of Cymbopogon nardus (L.) in different harvest times. Revista Ciencia Agronomica 41(2):308-314. DOI: https://doi.org/10.1590/S180666902010000200020 .

De Smet, PAGM. 1993. Borago officinalis. Adverse Effects of Herbal Drugs 2:147-152. DOI: https://doi. org/10.1007/978-3-642-48906-8_10.

Dixon, RA. 2001. Natural products and plant disease resistance. Nature 411:843-847. DOI: https://doi. org/10.1038/35081178.

Echavarría, A; D’Armas Regnault, H; Lisbeth, N; Matute, L; Jaramillo, C; Rojas de Astudillo, L; Benitez, R. 2016. Evaluación de la capacidad antioxidante y metabolitos secundarios de extractos de dieciséis plantas medicinales / Evaluation of antioxidant capacity and secondary metabolites of sixteen medicinal plants extracts. Ciencia Unemi 9(20):2935. DOI: https://doi.org/10.29076/issn.25287737vol9iss20.2016pp29-35p.
Eidi, S; Ghodrati Azadi, H; Ghanbari Nehbandani, H. 2014. Comparative Evaluation of the Antifungal Activity of Borage (Borago officinalis) and Camellia sinesis (Green tea) leaves against various Aspergillus and Candida strains. Journal of Biologically Active Products from Nature 4(1):29-36. DOI: https://doi. org/10.1080/22311866.2014.890063.

Ezziyyani, M; Pérez Sánchez, C; Requena, M; Sid Ahmed, A; Candela Castillo, M. 2004. Evaluación del biocontrol de «Phytophthora capsici» en pimiento (Capsicum annuиm L.) por tratamiento con «Burkholderia cepacia». Anales de biología (26):61-68.

Fabrikov, D; Guil-guerrero, JL; González-Fernández, MJ; Rodríguez-García, I; Gómez-Mercado, F; Urrestarazu, M; Teresa, M; Rincón-Cervera, MÁ; Álvaro, JE; Lyashenko, S. 2019. Journal of Food Composition and Analysis Borage oil : Tocopherols, sterols and squalene in farmed and endemic-wild Borago species. Journal of Food Composition and Analysis 83:103299. DOI: https://doi.org/10.1016/j. jfca.2019.103299.

Fernandes, L; Pereira, JA; Saraiva, JA; Ramalhosa, E; Casal, S. 2019. Phytochemical characterization of Borago officinalis L. and Centaurea cyanus L. during flower development. Food Research International 123:771-778. DOI: https://doi.org/10.1016/j. foodres.2019.05.014.

Galle, AM; Joseph, M; Demandre, C; Guerche, P; Dubacq, JP; Oursel, A; Mazliak, P; Pelletier, G; Kader, JC. 1993. Biosynthesis of $\gamma$-linolenic acid in developing seeds of borgae (Borago officinalis L.). BBA General Subjects 1158(1):52-58. DOI: https://doi. org/10.1016/0304-4165(93)90096-Q.

Galvano, F; Piva, A; Ritieni, A; Galvano, G. 2001. Dietary strategies to counteract the effects of mycotoxins: A review. Journal of Food Protection 64(1):120-131. DOI: https://doi.org/10.4315/0362-028X-64.1.120.

Gatto, MA; Ippolito, A; Linsalata, V; Cascarano, NA; Nigro, F; Vanadia, S; Di Venere, D. 2011. Activity of extracts from wild edible herbs against postharvest fungal diseases of fruit and vegetables. Postharvest Biology and Technology 61(1):72-82. DOI: https:// doi.org/10.1016/j.postharvbio.2011.02.005.

Geiser, DM; Jiménez-Gasco, MDM; Kang, S; Makalowska, I; Veeraraghavan, N; Ward, TJ; Zhang, N; Kuldau, GA; O'Donnell, K. 2004. FUSARIUM-ID v. 1.0: A DNA sequence database for identifying Fusarium. European Journal of Plant Pathology 110(5-6):473-479. DOI: https://doi.org/10.1023/ B:EJPP.0000032386.75915.a0.

Giraldo-Quintero, SE; Bernal-Lizarazú, MC; MoralesRobayo, A; Pardo-Lobo, AZ; Gamba-Molano, L. 2015. Descripción del uso tradicional de plantas medicinales en mercados populares de Bogotá, D.C. Nova 13(23):73. DOI: https://doi. org $/ 10.22490 / 24629448.1707$ 
Gómez-Fonnegra, R; Villa-Londoño, J. 2011. Plantas medicinales usadas en algunas veredas de municipios del altiplano del oriente antioqueño. Actualidades Biológicas 33(95):219-250.

Gressel, J. 2011. Low pesticide rates may hasten the evolution of resistance by increasing mutation frequencies. Pest Management Science 67(3):253-257. DOI: https://doi.org/10.1002/ps.2071.

Grimmer, MK; van den Bosch, Fk; Powers, SJ; Paveley, ND. 2015. Fungicide resistance risk assessment based on traits associated with the rate of pathogen evolution. Pest Management Science 71(2):207-215. DOI: https://doi.org/10.1002/ps.3781.

Hernández, J. 2012. Distribución y utilización de plaguicidas directrices sobre la prevención y manejo de la resistencia a los plaguicidas. s.l., s.e., vol. 3. 61 p.

Hobbelen, PHF; Paveley, ND; Van Den Bosch, F. 2011. Delaying selection for fungicide insensitivity by mixing fungicides at a low and high risk of resistance development: A modeling analysis. Phytopathology 101(10):1224-1233. DOI: https://doi.org/10.1094/ PHYTO-10-10-0290.

Hollomon, DW. 2012. Do we have the tools to manage resistance in the future? Pest Management Science 68(2):149-154. DOI: https://doi.org/10.1002/ps.2291.

ICA (Instituto Colombiano Agropecuario). 2019. Marchitez Por Fusarium Raza 4 Tropical-Foc R4T. Bogota, Colombia, s.e. s.p.

Jaeschke, H; Cover, C; Bajt, ML. 2006. Role of caspases in acetaminophen-induced liver injury. Life Sciences 78(15):1670-1676. DOI: https://doi.org/10.1016/j. lfs.2005.07.003.

Jasso de Rodríguez, D; Gaytán-Sánchez, NA; RodríguezGarcía, R; Hernández-Castillo, FD; Díaz-Jiménez, L; Villarreal-Quintanilla, JA; Flores-López, ML; Carrillo-Lomelí, DA; Peña-Ramos, FM. 2019. Antifungal activity of Juglans spp. and Carya sp. ethanol extracts against Fusarium oxysporum on tomato under greenhouse conditions. Industrial Crops and Products 138(May):111442. DOI: https:// doi.org/10.1016/j.indcrop.2019.06.005.

Kappel, VD; Costa, GM; Scola, G; Silva, FA; Landell, MF; Valente, P; Souza, DG; Vanz, DC; Reginatto, FH; Moreira, JCF. 2008. Phenolic content and antioxidant and antimicrobial properties of fruits of Capsicum baccatum L. var. pendulum at different maturity stages. Journal of Medicinal Food 11(2):267-274. DOI: https://doi.org/10.1089/jmf.2007.626.

Khafari, AZ; Bahraminejad, S; Abbasi, S. 2014. Evaluation of the anti-alternaria solani activity of allium hirtifolium boiss. Pakistan Journal of Botany 46(2):741-747.

Leon Duran, M; Mancheno Cardenas, M. 2021. Actividad antifúngica de compuestos frente a Fusarium graminearum Antifungal activity of tara
(Caesalpinia spinosa) Phenolic compounds against Fusarium graminearum 12(1):39-50.

Leos, C. 2010. Estudio de la actividad biológica de los extractos de tres plantas de la familia Boraginaceae por (en línea). s.l., Universidad Autónoma de Nuevo León. 108 p. Consultado 20 ene. 2020. Disponible en http://eprints.uanl.mx/id/eprint/2166

Lizcano González, MC. 2007. Evaluación de la actividad antifúngica del extracto de tomillo (Thymus vulgaris) contra Botrytis cinerea, Fusarium oxysporum y Sclerotinia sclerotiorum. Bogota, Colombia, Pontifica Universidad Javeriana $71 \mathrm{p}$.

Lock, O; Perez, E; Villar, M; Flores, D; Rojas, R. 2016. Bioactive compounds from plants used in peruvian traditional medicine. Natural Product Communications, USA. p. 1-10.

Lock, OR. 2016. Investigación Fitoquímica. Métodos en el estudio de productos naturales. Pontificia Universidad Católica del Perú (ed.). Lima, Peru, Pontificia Universidad Católica del Perú. 287 p.

Mahlo, SM; Mcgaw, LJ; Eloff, JN. 2010. Antifungal activity of leaf extracts from South African trees against plant pathogens. Crop Protection 29(12):1529-1533. DOI: https://doi.org/10.1016/j.cropro.2010.08.015.

Marquez-Vizcaino, R; De la Rosa-Torres, C; MercadoPérez, A. 2007. Actividad antifúngica del extracto total en etanol de las hojas frescas de pedilanthus tithymaloides 1 poit (ultimorrial). Scientia et Technica 1(33):155-159. DOI: https://doi. org/10.22517/23447214.6171.

Mesa, A; Marin Pavas, D; Ocampo, O; Calle, J; Monsalve, Z. 2019. Fungicidas a partir de extractos vegetales: Una alternativa en el manejo integrado de hongos fitopatógenos. Revista de Investigaciones Agropecuarias 45(1):23-30.

Mhamdi, B; Wannes, WA; Bourgou, S; Marzouk, B. 2009. Biochemical characterization of borage (Borago officinalis L.) seeds. Journal of Food Biochemistry 33(3):331-341. DOI: https://doi.org/10.1111/j.17454514.2009.00221.x.

Miceli, A; Aleo, A; Corona, O; Sardina, MT; Mammina, C; Settanni, L. 2014. Antibacterial activity of Borago officinalis and Brassica juncea aqueous extracts evaluated invitro and in situ using different food model systems. Food Control 40(1):157-164. DOI: https://doi.org/10.1016/j.foodcont.2013.12.006.

Moreno-Velandia, CA; Cotes, AM; Beltrán-Acosta, C; Bettiol, W; Elad, Y. 2018. Control biológico de fitopatógenos del suelo. s.l., Agrosava. p. 204.

Moreno, JP. 2011. Actividad antifúngica de los extractos vegetales de Piper eriopodon y Zanthoxylum monophyllum y sus metabolitos secundarios mayoritarios sobre dos hongos fitopatógenos de clavel (Dianthus caryophyllus). s.1., Universidad Nacional de Colombia. 159 p. 
Nabavi, SM; Ebrahimzadeh, MA; Nabavi, SF; Jafari, M. 2008. Free radical scavenging activity and antioxidant capacity of Eryngium caucasicum Trautv and Froripia subpinnata. Pharmacologyonline 3:1925.

Navarrete, KB; Jaramillo, CJ; Martín, DS; D’Armas, H. 2017. Estudio de la calidad bacteriológica de doce plantas medicinales de uso común en Ecuador (en línea). Facsalud-Unemi 1(1):12-17. Consultado 15 nov. 2019. Disponible en http://ojs.unemi.edu.ec/ojs/ index.php/facsalud-unemi/article/view/539/452

Nieto-Navarro, F. 2012. Evaluación de la actividad antifúngica de plantas medicinales de baja california sur contra Fusarium oxysporum en albahaca (Ocimum basilicum L.). s.1., Universidad Autónoma de Baja California Sur. La Paz, B.C.S, Mexico. 58 p.

Nychas, GJE. 1995. Natural antimicrobials from plants. s.1., s.e. DOI: https://doi.org/10.1007/978-1-46152105-1_4.

Okwu, D; Nmamdi, FU. 2008. Evaluation of the chemical composition of Dacryodes edulis and Raphia hookeri mann and wendl exudates used in herbal medicine in south eastern nigeria. African Journal of Traditional, Complementary and Alternative Medicines 5:194-200.

Pal, KK; Gardener, BM. 2006. Biological Control of Plant Pathogens. The Plant Health Instructor p. 1-25. DOI: https://doi.org/10.1094/PHI-A-2006-1117-02.

Pavón-Moreno, MÁ; González-Alonso, I; Martín de Santos, R; García-Lacarra, T. 2012. Importancia del género Alternaria como productor de micotoxinas y agente causal de enfermedades humanas. Nutricion Hospitalaria 27(6):1772-1781. DOI: https://doi. org/10.3305/nh.2012.27.6.6017.

Pietarinen, SP; Willför, SM; Vikström, FA; Holmbom, BR. 2006. Aspen knots, a rich source of flavonoids. Journal of Wood Chemistry and Technology 26(3):245-258. DOI: https://doi.org/10.1080/02773810601023487.

Rangel-Castillo, A. Eugenia; Valadez-Moctezuma, Ernestina; Lozoya Saldaña, H. 2017. Caracterización molecular y patogénesis de Fusarium asociado al amarillamiento del trigo Fusarium associated to wheat yellowing. Rev. Fitotec. Mex 40(4):439-450.

Ratz-Łyko, A; Herman, A; Arct, J; Pytkowska, K. 2014. Evaluation of antioxidant and antimicrobial activities of Oenothera biennis, Borago officinalis, and Nigella sativa seedcake extracts. Food Science and Biotechnology 23(4):1029-1036. DOI: https:// doi.org/10.1007/s10068-014-0140-2.

Ravindran, R; Juliet, S; Gopalan, AKK; Kavalimakkil, AK; Ramankutty, SA; Nair, SN; Narayanan, PM; Ghosh, S. 2011. Toxicity of DMSO, Triton X 100 and Tween 20 against Rhipicephalus (Boophilus) annulatus. Journal of Parasitic Diseases 35(2):237-239. DOI: https://doi.org/10.1007/s12639-011-0054-3.

Reddy, MK; Gupta, SK; Jacob, MR; Khan, SI; Ferreira, D. 2007. Antioxidant, antimalarial and antimicrobial activities of tannin-rich fractions, ellagitannins and phenolic acids from Punica granatum L. Planta Medica 73(5):461-467. DOI: https://doi. org/10.1055/s-2007-967167.

Robles, M; Aguilar, J; Gutiérrez, M; Rodríguez, F; Morales, J; Guerrero, P; Madrigal, J; Del Toro, C. 2016. Identificación cualitativa de metabolitos secundarios y determinación de la citotoxicidad de extractos de tempisque (Sideroxylum capiri Pittier). Biotecnia XVIII (3):3-8. DOI: https://doi. org/10.18633/BIOTECNIA.V18I3.328.

Rodríguez-Maturino, A; Troncoso-Rojas, R; SánchezEstrada, A; González-Mendoza, D; Ruiz-Sánchez, E; Zamora-Bustillos, R; Ceceña-Duran, C; Grimaldo-Juárez, O; Aviles-Marin, M. 2015. Efecto antifúngico de extractos fenólicos y de carotenoides de chiltepín (Capsicum annum var. glabriusculum) en Alternaria alternata y Fusarium oxysporum. Revista Argentina de Microbiología 47(1):72-77. DOI: https://doi.org/10.1016/j.ram.2014.12.005.

Saadatian, M; Aghaei, M; Farahpour, M; Aghaei, M. 2017. Chemical Compositions of Flowers extract of Borage (Borago officinalis L.) in wild population from Urmia district, Iran. Journal of Essential OilBearing Plants 20(1):289-292. DOI: https://doi.org/1 0.1080/0972060X.2015.1086283.

Salazar-González, C; Serna-Cock, L; Gómez-López, E. 2016. Caracterización molecular de Fusarium asociado a pudrición basal del fruto en pitahaya (Selenicereus megalanthus). Agronomía Mesoamericana 27(2):277. DOI: https://doi.org/10.15517/am.v27i2.21269.

Salazar, C. 2016. Caracterización molecular y morfológica de aislamientos de Fusarium spp. productores de micotoxinas (en línea). s.l., Universidad Nacional de Colombia. 103 p. Consultado 06 dic. 2019. Disponible en http://www.bdigital.unal.edu. co/53757/

Sánchez-Recillas, A; Aragón-Castillo, SL; Arroyo-Herrera, AL; Araujo-León, JA; Ortiz-Andrade, RR. 2020. Efecto espasmolitico y antibacteriano de la especie Bursera graveolens (Kunth). Polibotánica 0(49):135147. DOI: https://doi.org/10.18387/polibotanica.49.9.

Saúl, J; Pérez, B; Montes-belmont, R; Ayala, FC; Floresmoctezuma, HE; Angel, M; Cruz, S. 2011. Propiedades antifúngicas en especies del género Tagetes. Revista Mexicana de Micología 34:83-88.

Segovia, F; Lupo, B; Peiró, S; Gordon, MH; Almajano, MP. 2014. Extraction of antioxidants from borage (Borago officinalis L.) leaves-optimization by response surface method and application in oil-inwater emulsions. Antioxidants 3(2):339-357. DOI: https://doi.org/10.3390/antiox3020339.

Simpson, MJA. 1993. A description and code of development of borage Borago officinalis. Annals of Applied Biology 123(1):187-192. DOI: https://doi. org/10.1111/j.1744-7348.1993.tb04085.x. 
Siva, N; Ganesan, S; Banumathy, N. 2008. Antifungal effect of leaf extract of some medicinal plants against Fusarium oxysporum causing wilt disease of Solanum melogena L. Ethnobotanical Leaflets 12:156-163.

Soylu, EM; Kurt, Ş; Soylu, S. 2010. In vitro and in vivo antifungal activities of the essential oils of various plants against tomato grey mould disease agent Botrytis cinerea. International Journal of Food Microbiology 143(3):183-189. DOI: https://doi. org/10.1016/j.ijfoodmicro.2010.08.015.

Tirumale, S; Wani, N. 2018. Biological control of phytopathogenic fungi using different extracts of chaetomium cupreum. Asian Journal of Pharmaceutical and Clinical Research 11(9):328332. DOI: https://doi.org/10.22159/ajpcr.2018. v11i9.26836

Vanegas Berrouet, KM; Gutiérrez Sánchez, PA; Marín Montoya, MA. 2014. Molecular Identification of Fungi Isolated from Bean Tissues with Anthracnose Symptoms. Acta Biológica Colombiana 19(2):143. DOI: https://doi.org/10.15446/abc.v19n2.39154.
Villavicencio, SA. 2013. Identificación molecular de aislados de hongos nematófagos asociados a Meloidogyne hapla Chitwood. (en línea). s.l., Universidad Austral de Chile. 66 p. Consultado 06 dic. 2019. Disponible en http://www.ncbi.nlm.nih.gov.myaccess.library. utoronto.ca/pubmed/11720961

White, TJ; Bruns, T; Lee, S; Taylor, J. 1990. Amplification and direct sequencing of fungal ribosomal RNA genes for phylogenetics. s.1., s.e. DOI: https://doi. org/10.1016/b978-0-12-372180-8.50042-1.

Zemmouri, H; Ammar, S; Boumendjel, A; Messarah, M; El Feki, A; Bouaziz, M. 2014. Chemical composition and antioxidant activity of Borago officinalis L. leaf extract growing in Algeria. Arabian Journal of Chemistry 12(8):1954-1963. DOI: https://doi org/10.1016/j.arabjc.2014.11.059.

Zheng, W; Wang, S. 2007. Antioxidant activity and phenolic compounds in 32 selected herbs. Food Chemistry 105(3):940-949. DOI: https://doi.org/10.1016/j. foodchem.2007.04.038.

Todos los derechos reservados. Universidad de Costa Rica. Este artículo se encuentra licenciado con Creative Commons Reconocimiento-NoComercial-SinObraDerivada 3.0 Costa Rica. Para mayor información escribir a rac.cia@ucrac.cr 
